\title{
Analysis of Employee Attrition using for Machine Learning Techniques
}

\author{
Sadineni Sanjeetha ${ }^{1}$, Ch.V. Phani Krishna ${ }^{2}$ \\ ${ }^{1}$ PG Scholar,Department of Computer Science and Engineering, \\ ${ }^{2}$ Professor, Department of Computer Science and Engineering, \\ Teegala Krishna Reddy Engineering College, Meerpet, Hyderabad, Telangana 500097
}

Article History:Received:11 november 2020; Accepted: 27 December 2020; Published online: 05 April 2021

\begin{abstract}
Nowadays, the daily forecast for employee losses becomes a major issue. Staff participation is an important issue for the organization, especially when professional technical staff and key people in the organization come from good positions. This leads to a loss of finances to replace skilled labor. Therefore, we use data from current and former employees to analyze common causes of employee access or influence. To avoid employment, we use several planning methods, namely: Decision Tree, Log-log of Backlog, SVM, KNN, Random Forest, Bayes Naive. To do this, we use the method to select employment information and analyze the results to avoid employee income. Companies need to anticipate employee incentives and contribute to economic growth by reducing manpower.
\end{abstract}

\section{Keywords:.}

\section{INTRODUCTION}

Employees can join or leave the company because of many factors, such as work environment, central management, gender equality, law, etc. Examples of employee comfort can be personal reasons related to the placement of family, mother, health, stress, and management or physical partner. Law enforcement is a major concern for the group, especially when professional staff is the key to a good company. As a result, hardworking employees suffer financial losses. That is why we use words and gifts with difficulty, from family work to the part that matters.

Identity cards allow employees to anticipate and solve problems that interest us. This information can be used to create personal effects.

To achieve this, we use many recording methods. Each point represents a specific problem; each branch represents a point and each leaf represents. Social symbols), Bays Naive (Bayesian unit according to Bayesian Theoretical Center) Vie states that the existence a specific genus has nothing to do with other lifestyles, such as fruit. Most families choose apples) Some income is greater than the capacity required, in the community of support vector machines (SVM) split into two classes and disagree on the meaning of their lives), Captain KNeighbor (KNN) and random forest) IBM type k choice HR has been found to support database technology. Database data from 1470 of 35 data and functions, and some instructions Needed to process the database in advance (if you think the value of a document should be evaluated in the document or its meaning is unclear, leave all documents in the textbook in the textbook, get more information on the basic data and all the functions of the hearing aid). And implement collective collections in a unique database. One way to see the problem is to read the information. Documents and databases that are not currently available at the school are needed to ensure all activities are needed to reflect the interests or preferences of the staff. Finally, we use the methods used in the above class tests and the number of references to achieve the results you want so that you are not influenced by the staff.

\subsection{MOTIVATION:}

Entering or leaving an organization from an organization depends on many factors, including the work environment, workplace, gender equality, wages, and many other factors. Some employees thought about family relocation, birth, health issues, and personal reasons, such as co-chairs or team members. Leaving staff is a key issue for organizations, especially when they are trained, which provides a good opportunity to manage technology with key players. Ultimately, this leads to the loss of money other than trained employees. Therefore, we use current and past employee data to evaluate family issues based on employee issues.

Identifying clothing staff can assist and resolve clothing issues. We may use this information to increase employee engagement.

In this work, we use different ways of sharing data. This method is a solution tree (this is a tree structure that has branches, root nodes, and leaf fragments. Each node represents test properties, each branch represents test results and each node has behavioral nodes), Naive Bayes (This classification method is based on Bayesian Theory the division assumes that the existence of the class in the classroom has nothing to do with the existence of other assets)

\subsection{PROBLEM FORMULATION:}


Add unstructured data, text data to standard id. As a result, the performance of the identification function was analyzed. Research confirms the manufacturer's decision to add buyers and said it can be against members.

\subsection{OBJECTIVE:}

We search for information and analyze past and present employees to assess future impacts and to investigate the causes of unemployment. The research describes data acquisition algorithms, based on the data entry method methods that can be developed those employees deem appropriate.

\section{LITERATURE SURVEY}

New insights into a churn prediction in the telecommunication sector a profit-driven data-mining approach

The registration delivery model is designed to quickly identify land buyers, increase the effectiveness of their customer protection campaigns, and reduce associated costs. Although the main goal is to reduce costs, graphical predictions are usually used to measure the effect on statistics, which usually selects larger models. Thus, the level of employment benefits, based on the absence of candidates who are expected to set campaign records, is calculated in the first part of this new volume by calculating the maximum profit. Choose the size of the new model and the best part of the client to enter, and as a result, there will be a significant increase in revenue and number of figures.

In the second part, comparative evaluation experiments are often conducted to evaluate how data from eleven global operators work based on performance and statistics. Experimental results show that a small number of variables can be accurately predicted with high accuracy, and the size does not increase the effect at all. Eventually, the group found that all my classmates gave the same results.

\section{Connect client voice to call center email and customer support decision-making system}

We address the issue of increasing DSS production to predict circulation. In particular, the impact of increasing revenue on clients is analyzed using telephone centers - information technology. When this additional information is available, the data from the experimental model form a model close to nuclear power, which means that the performance forecast is greatly improved. From a management point of view, an integrated decision-making system that supports the buyer should identify potential customers. This way, the customers who serve your campaign can be interpreted as the first way to know in advance who can leave.

\section{Telecommunication data interpretation predicts data loss: data mining methods}

In general, new technologies and new competitors face the industry and predict that basic maintenance has become a major issue for mobile operators. Mobile operators who want to register must first be aware of the risk of transferring work and attracting customers to the user. There is no external system other than the telecommunications system, we recommend, develop, and evaluate the demolition court approach which aims to reduce contract information and change the structure of the telephone. Je! How do you judge the proposed tenant during the projection period? Besides, the proposed approach is to articulate sectoral strategies against resistance to class divisions, distributors who are very complex with other practitioners. The evaluation results show that when the phone is used to create a new fall forecast model, it is the power of the left forecast that is modified and shows a satisfactory effect. Besides, it is recommended that the method be able to assess the strength or mean time between the development model and the predictable memory. Using the basic forecasting system as part of the record, the effect of the forecast obtained by the technology is impressive.

\section{OVERVIEW OF THE SYSTEM}

\subsection{Existing System:}

Add the address that is posted directly to the traditional exhaust definition. As a result, public awareness of local identity has increased. The previously released video weapon promises a potentially deported lawyer.

\subsection{Disadvantages of the existing system:}

Now, the system uses several methods and remains the only truth.

Tired employees can cause financial loss and waste time and effort in the company. This is an important issue that indicates that it is difficult and best to replace skilled and unskilled workers.

\subsection{Proposed System:}

Data set:

The activity is collecting data. The data structure usually stores the contents of the database in each column of the table that corresponds to the selected parameters and in each data column in the data. In our project, we received information from IBM staff based on numbers 1470 and 35 and from field locations. Each report states that the package contains information about each employee and each location, which is a unique public service.

\section{Data pre-processing:}

To set up the IBM data crew, we used the appropriate working method to select the most important data storage function and divide all the data into two layers. If the message does not state values that do not include costs or costs, or if you do not consider them valuable, only the information received from the type and field of information will be disseminated in the training package until it has the correct facts and characteristics in the document. has then automatically changed according to the information. The book contains all data usage services. Staff uniforms or school uniforms and data sets contain more reliable information. 
Test dataset and training dataset:

The database is the part of the school that looks at data structure and data exchange. It is important to compare data collection models. Because the data variation is determined by the device data, we will not affect the reference data and understand the larger version services. Posting tests do not require all the items needed to identify school items and information, and not all information is required.

Here we got 788 and 682 items in the package. We see correct groups and predictions recorded in 788-word views and data levels.

\section{Data classification techniques:}

Collecting data in a group is the simplest and most efficient data management system. One type of strategic information is the decision tree

Decision Tree: The tree has roots, branches, and stems. They always represent the property, each branch, the end of the experiment, and the social symbols for each file.

\subsection{Advantages of Proposed system}

We try to calculate the number and the former job will reduce fatigue later and investigate the causes of employee changes. Considering that light effects can be used to create intervention strategies, data extraction settings are considered complete and complete.

\section{OUTPUT SCREEN SHOTS}

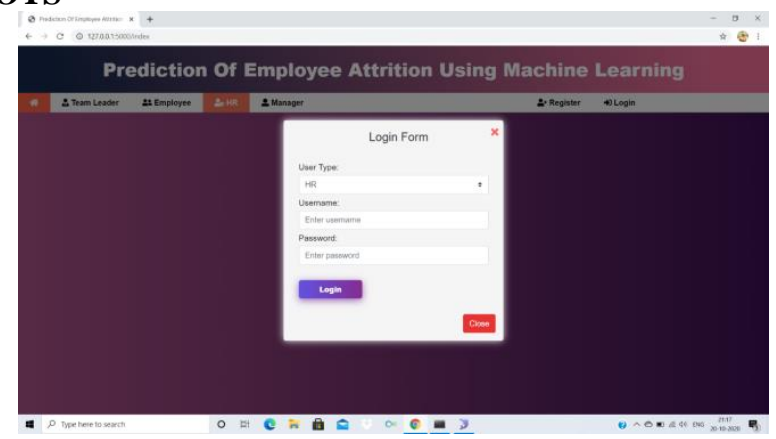

\section{CONCLUSION}

The government has reduced the fatigue, time, and manpower of financial workers. The biggest challenge is that skilled workers become more skilled and successful even re-engineered. We look for reasons to turn, knowing that employees who are past and present care about the goal. Je! What does the information removal algorithm mean to create a reliable and accurate way to predict social fatigue? The problem of identity fatigue is not always fatigue. With the help of advertising information and data collection techniques, we allow every employee to demonstrate their capabilities and create a copy-storage strategy.

\section{REFERENCES}

W. Verbeke, K. Dejaeger, D. Martens, J. Hur, and B. Vaesens," New insights into a churn prediction in the telecommunication sector.An profit-driven data mining approach," European journal of operational research, vol. 218, no. 1, pp. 211-229, 2012.

K.Coussement and D. VandenPoel, "Integrating the voice of customers through call center emails into a decision support system for attrition prediction," Information \& Management, vol. 45, no. 3, pp. 164-174, 2008.

C.-P. Wei and I.-T. Chiu, "Turning telecommunications call details to attrition prediction: a data mining approach," Expert systems with applications, vol. 23, no. 2, pp. 103-112, 2002.

K. Coussement and D. Van den Poel, "Attrition prediction in subscription services: An application of support vector machines while comparing two parameter-selection techniques," Expert systems with applications, vol. 34, no. 1, pp. 313-327, 2008.

J. Bures and D. Van den Poel, "Handling class imbalance in customer attrition prediction," Expert Systems with Applications, vol. 36, no. 3, pp. 4626-4636, 2009.

C.-F. Tsai and M. Y. Chen, "Variable selection by association rules for customer attrition prediction of multimedia on-demand," Expert Systems with Applications, vol. 37, no. 3, pp. 2006-2015, 2010.

K. Coussement, D. F. Benoit, and D. Van den Poel, "Improved marketing decision making in a customer attrition prediction context using generalized additive models," Expert Systems with Applications, vol. 37, no. 3, pp. 2132-2143, 2010

B. Huang, M. T. Kechadi, and B. Buckley, "Customer attrition prediction in telecommunications," Expert Systems with Applications, vol. 39, no. 1, pp. 1414-1425, 2012

V. V. Saradhi and G. K. Palshikar, "Employee attrition prediction," Expert Systems with Applications, vol. 38, no. 3, pp. 1999-2006, 2011. 
R. Khare, D. Kaloya, C. K. Choudhary, and G. Gupta, "Employee attrition risk assessment using logistic regression analysis,". 